\title{
CORONARY ARTERY DISEASE (CAD); INTERMEDIATE CAD WITH FFR (FRACTION FLOW RESERVE) EVALUATION
}

1. MBBS, FCPS (Cardiology) Assistant Professor Cardiology Madina Teaching Hospital, UMDC Faisalabad.

2. MBBS, FCPS (Cardiology) FACC (USA), DIP- CARD (Pb), Associate Professor of Cardiology, Faisalabad Institute of Cardiology, Faisalabad.

3. Medical Officer Faisalabad Institute of Cardiology, Faisalabad.

Correspondence Address: Dr. Naeem Asghar Assistant Professor Cardiology Madina Teaching Hospital, UMDC Faisalabad. dearnaeem06@gmail.com

Article received on: $07 / 11 / 2016$

Accepted for publication: 30/12/2016

Received after proof reading: $18 / 01 / 2017$

\section{Dr. Naeem Asghar ${ }^{1}$, Dr. Liaqat $\mathrm{Ali}^{2}$, Dr. Asadullah ${ }^{3}$}

ABSTRACT... Background: Coronary artery lesion severity is physiological assessed by fractional myocardial flow reserve (FFR). Angiographic assessment of intermediate severity lesions is problematic as inter-observer variability is significant. Hence one is not sure about the hemodynamic or functional significance of these lesions. FFR is helpful in this situation by assessing functional or hemodynamic significance of these intermediate coronary lesions. An FFR value $<0.80$ identifies ischemia-causing coronary stenosis with an accuracy of $>90 \%$ suggesting that intermediate coronary lesion is in fact functionally important. Objective: To determine the correlation between mean lesion length of diffuse intermediate stenosis $(40 \%$ $70 \%$ stenosis) of proximal and mid segment of major coronary arteries and mean fractional flow reserve (FFR). Study duration: From 1-07-2015 to 31-12-2015. Study design: Cross sectional study. Methodology: After approval from hospital Ethical committee and Informed consent, 60 patients with intermediate diffuse lesions on coronary angiography from Faisalabad Institute of Cardiology were enrolled. FFR assessment of diffuse intermediate lesion was done by author. FFR assessment was done using FFR wire during maximal blood flow (hyperemia) which was induced by injecting bolus dose of intracoronary adenosine. The cost of procedure was managed by hospital. Results: In this study, $28.33 \%(n=17)$ were between $20-50$ years of age, mean+SD was calculated as $55.17+8.04$ years, $51.67 \%(n=31)$ were male and $48.33 \%(n=29)$ were females. Correlation between mean lesion length of diffuse intermediate stenosis $(40 \%$ $70 \%$ stenosis) of proximal and mid segment of major coronary arteries and mean fractional flow reserve (FFR) was recorded it shows that mean lesion length was $24.53+4.78 \mathrm{~mm}$ while FFR was recorded as $0.72+0.12$, the value of $R$ is -0.1928 , technically a negative correlation, the relationship between variables is only weak (the nearer the value is to zero, the weaker the relationship). The value of $\mathrm{R}^{2}$, the coefficient of determination, is 0.0372 . Conclusion: The correlation between mean lesion length of diffuse intermediate stenosis (40\%-70\% stenosis) of proximal and mid segment of major coronary arteries and mean fractional flow reserve (FFR) was weak and did not suggest any hemodynamic significance of diffuse intermediate coronary artery lesions.

Key words: $\quad$ Coronary artery disease (CAD), fractional flow reserve (FFR).

Article Citation: Asghar N, Ali L, Asadullah. Coronary Artery Disease (CAD); Intermediate CAD with FFR (Fraction flow reserve) evaluation. Professional Med J 2017;24(1):2125. DOI: $10.17957 / \mathrm{TPMJ} / 17.3716$

\section{INTRODUCTION}

Coronary artery disease (CAD) is one of leading causes of morbidity and mortality worldwide..$^{1,2}$ Atherosclerosis is a diffuse process, so it is not uncommon to find diffuse intermediate coronary artery disease on coronary angiography producing blood turbulence in coronary lumen resulting impaired blood flow and myocardial ischemia. ${ }^{3,4}$ Coronary artery lesions can be assessed both anatomical and physiologically. Coronary angiography is the gold standard method for anatomical evaluation while intravascular ultrasound (IVUS) further improves anatomical evaluation. The physiological assessment of myocardial ischemia is by fractional myocardial flow reserve (FFR). Coronary Angiography has certain limitations in assessing hemodynamic or functional significance of diffuse intermediate stenosis ${ }^{5}$ hence these lesions are not considered to be suitable for revasularization. ${ }^{6}$ Although quantitative coronary angiography (QCA) reduced these limitations but cannot determine the severity and functional importance of diffuse intermediate coronary lesions ${ }^{7}$. Any stenotic 
lesion in the coronary vessel that induces ischemia if vascularized improves clinical outcome. ${ }^{8}$ Performing $\mathrm{PCl}$ on non- ischemic stenosis is not beneficial and is probably harmful. ${ }^{9}$

In the last few years, the physiological assessment of coronary stenosis with fractional flow reserve (FFR) is useful diagnostic and prognostic modality. FFR is the ratio between distal and proximal pressures of lesion under conditions of maximal hyperemia ${ }^{10}$ and is indicated in coronary lesions of intermediate angiographic severity (40-70\%). ${ }^{11}$ FFR of normal coronary artery is widely accepted as 1.0. CAD resulting in significant ischaemia if value of FFR is $<0.80$ and it is $>90 \%$ accurate. ${ }^{12}$

In this study the hemodynamic significance of diffuse intermediate CAD by FFR is determined which is valuable tool for assessing myocardial ischemia otherwise these diffuse intermediate lesions may be neglected on just visual assessment on coronary angiography, so that we can offer early treatment and revascularization of these significant lesions.

\section{Objective}

To determine the correlation between mean lesion length of diffuse intermediate stenosis (40\%$70 \%$ stenosis) of proximal and mid segment of major coronary arteries and mean fractional flow reserve (FFR).

\section{OPERATIONAL DEFINITIONS}

\section{Fractional Flow Reserve (FFR)}

Measurement of pressure differences across a coronary artery stenosis during coronary catheterization to determine ischemic significance of stenosis.

Hemodynamic or Functional Significance of Coronary Stenosis

Stenosis of coronary vessel is significant if it induces ischemia (decrease blood supply to heart) in case of stress.

Intermediate coronary artery stenosis Coronary artery luminal narrowing of $40 \%$ to $70 \%$ on coronary angiography.

\section{Major coronary arteries}

The three major coronary arteries, Left Anterior Descending (LAD), left Circumflex (LCX) and Right Coronary Artery (RCA).

\section{Quantitative coronary angiography}

It is a computerized process that determines the degree of stenosis or narrowing in coronary arteries.

\section{Diffuse Coronary Lesions}

Lesions that exceed $2 \mathrm{~cm}(20 \mathrm{~mm})$ in length

Proximal and mid segment of left anterior descending artery (LAD)

The portion of the artery between left main stem and origin of $1^{\text {st }}$ major septal branch is proximal segment while the segment of LAD after $1^{\mathrm{ST}}$ septal branch to angle of heart (RAO view).

\section{Proximal portion of circumflex artery (LCX)}

The portion of the artery prior to the origin of the $1^{\text {ST }}$ obtuse marginal branch $(\mathrm{OM}-1)$.

\section{Proximal and mid portion of right coronary} artery (RCA)

Proximal segment starts from its origin to one half of distance to acute margin of heart. Mid segment starts from end of proximal part to acute margin of heart.

\section{MATERIAL AND METHODS}

Setting

Department of Cardiology, Faisalabad Institute of Cardiology, Faisalabad.

\section{Study duration}

From 1-07-2015 to 31-12-2015.

\section{Study design}

Cross sectional study.

Sample size

- By using correlational sample size calculator: $r=0.63$ 
Type 1 error $=5 \%$

Type 2 error $=10 \%$

Sample size $=60$

Confidence level $=95 \%$

\section{SAMPLE TECHNIQUE}

Non probability, purposive sampling

\section{Inclusion Criteria}

Following patients was included in the study.

- Age 20-70 years

- Either sex

- All lesions of moderate angiographic stenosis (40-70\% stenosis on QCA) and a lesion length of $>20 \mathrm{~mm}$.

\section{Exclusion Criteria}

- Recent myocardial infarction within 6 months

- Acute coronary syndrome

- Lesions with collateral vessels

- Patients having valvular heart disease

- Patients with deranged renal function (serum creatinine $>1.8$ )

- Cardiogenic shock (systolic blood pressure $<90 \mathrm{mmHg}$ with signs of poor perfusion)

- Left ventricular systolic dysfunction (ejection fraction $<40 \%$ )

- Patient having previous history of revascularization.

- Those with angiographic signs of instability such as thrombus (Spherical intraluminal filling defect), dissection (a tear causing blood to flow between the layers of coronary vessel which forces them apart)

\section{DATA COLLECTION PROCEDURE}

After approval from hospital Ethical committee and informed consent, 60 patients were selected having intermediate diffuse lesions on coronary angiography from Faisalabad Institute of Cardiology. After routine investigations, FFR assessment of diffuse intermediate lesion was done. For FFR assessment, adenosine induced hyperemia FFR wire is used to measure pressure. $300-500 \mu \mathrm{g}$ of intracoronary adenosine is given during FFR assessment procedure. The information was documented.

\section{DATA ANALYSIS}

All the data was entered and analyzed by using SPSS V-16. Mean and standard deviation was calculated for all the quantitative variables like age, lesion length and FFR. Frequency and percentage was calculated for the qualitative variables like gender. Pearson correlation was applied. Significant P-value was $<0.05$.

\section{RESULTS}

Cases fulfilling the inclusion/exclusion criteria were enrolled. Age distribution of the patients was done showing that $28.33 \%(n=17)$ were between 20-50 years of age, mean+SD was calculated as $55.17+8.04$ years. (Table No. I). Gender distribution of the patients shows that $51.67 \%(n=31)$ were male and $48.33 \%(n=29)$ were females. (Table No. II).

Correlation between mean lesion length of diffuse intermediate stenosis (40\%-70\% stenosis) of proximal and mid segment of major coronary arteries and mean fractional flow reserve (FFR) was recorded it showed that mean lesion length was $24.53+4.78 \mathrm{~mm}$ while FFR was recorded as $0.72+0.12$, the $R$ value is -0.1928 , technically a negative correlation, hence relationship between variables is only weak (the nearer the value is to zero, the weaker the relationship). The value of $R^{2}$, the coefficient of determination, is 0.0372 . (Table No. III)

\begin{tabular}{|c|c|c|}
\hline Age(in years) & No. of patients & $\%$ \\
\hline $20-50$ & 17 & 28.33 \\
\hline $51-70$ & 43 & 71.67 \\
\hline Total & $\mathbf{6 0}$ & $\mathbf{1 0 0}$ \\
\hline Mean+SD & \multicolumn{2}{|c|}{$\mathbf{5 5 . 1 7 + 8 . 0 4}$} \\
\hline Table-I. Age distribution $(\mathrm{n}=\mathbf{6 0})$ \\
\hline Gender & No. of patients & $\%$ \\
\hline Male & 31 & 51.67 \\
\hline Female & 29 & 48.33 \\
\hline Total & $\mathbf{6 0}$ & $\mathbf{1 0 0}$ \\
\hline
\end{tabular}

Table-II. Gender distribution $(n=60)$

\begin{tabular}{|c|c|c|}
\hline Lesion length/FFR & Mean & SD \\
\hline Lesion length & 24.53 & 4.78 \\
\hline FFR & 0.72 & 0.12 \\
\hline Table-III. Correlation between mean lesion length \\
mean fractional flow reserve (FFR) $(n=60)$
\end{tabular}


The value of $R$ is -0.1928 .

Statistically a negative correlation, the relationship between variables is only weak. The value of $\mathrm{R}^{2}$, the coefficient of determination, is 0.0372 .

\section{DISCUSSION}

This study was planned with the view to determine the hemodynamic significance of diffuse intermediate lesions by FFR which is valuable tool for assessing myocardial ischemia.

In our study, $28.33 \%(n=17)$ were between 20 50 years of age, mean+SD was calculated as $55.17+8.04$ years, $51.67 \%(n=31)$ were male and $48.33 \%(n=29)$ were females. Correlation between mean lesion length of diffuse intermediate stenosis (40\%-70\% stenosis) of proximal and mid segment of major coronary arteries and mean fractional flow reserve (FFR) was recorded it shows that mean lesion length was $24.53+4.78 \mathrm{~mm}$ while FFR was recorded as $0.72+0.12, R$ is -0.1928 , statistically suggesting only a weak relationship. The value of $R^{2}$, the coefficient of determination, is 0.0372 . A similar study was conducted by López-Palop $R$ et $\mathrm{al}^{13}$ in which correlation between Fractional Flow Reserve (FFR) and lesion length was found to be significant ( $r$ : 0.63) however our findings are in contrast with this study being weak correlation.

Iguchi $\mathrm{T}$ and others ${ }^{14}$ studied coronary lesions based on QCA data. They considered cases as intermediate stenosis (group I) with $40 \%$ to $70 \%$ stenosis and significant stenosis (group S) with $\geq 70 \%$ stenosis. Their objective was to determine functional significance of lesion length in intermediate coronary disease. In group S inverse correlation between the percentage of diameter stenosis (\%DS) and FFR in group $S(r=-0.83, P<$ $0.0001)$ while in group I, no significant correlation was found between \%DS and FFR $(r=-0.06, P$ $=0.55$ ), whereas lesion length was significantly inversely correlated with FFR $(r=-0.79, P<$ $0.0001)$. Receiver operating characteristic curve analysis demonstrated that the best cutoff value for predicting an FFR value $<0.80$ was a lesion length $>16.1 \mathrm{~mm}$ in group I (sensitivity, 86\%; specificity, 94\%) and concluded that the lesion length in intermediate-grade coronary lesions has a physiologically significant impact.

Brosh $D$ et al $^{15}$ evaluated intermediate-grade lesions (63 patients) with FFR. Quantitative coronary angiography (QCA) analysis was used to determine lesion length and percent diameter stenosis (\% DS). They concluded that lesion length has a significant impact on the physiological significance of intermediate-grade coronary lesions.

Though previous studies have shown a significant strong relation between lesion length and FFR. Our relation was weak, it may be due to smaller sample size in our study or use of bolus technique of adenosine administration vs continuous infusion.

\section{CONCLUSION}

In our study the correlation between mean lesion length of diffuse intermediate stenosis (40\%-70\% stenosis) of proximal and mid segment of major coronary arteries and mean fractional flow reserve (FFR) was weak, it may be due to smaller sample size of our study or use of bolus technique of adenosine administration vs continuous infusion. Copyright (C) 30 Dec, 2016.

\section{REFERENCE}

1. Khashaba A, Mortada A, Omran A. Intracoronary versus intravenous adenosine-induced maximal coronary hyperemia for fractional flow reserve measurements. Clin Med Insights Cardiol. 2014;8:1721.

2. Nadeem M, Ahmed S, Mansoor S, and Farooq S. Risk factors for coronary heart disease in patients below 45 years of age. Pak J Med Sci. 2013;29:91-6.

3. Iguchi T, Hasegawa T, Nishimura S, Nakata S, Kataoka $\mathrm{T}$, Ehara $\mathrm{Sn}$. Impact of lesion length on functional significance in intermediate coronary lesions. Clin Cardiol. 2013;36:172-7.

4. López-Palop R, Carrillo P, Cordero A, Frutos A, Mateo I, Mashlab S. Effect of lesion length on functional significance of intermediate long coronary lesions. Catheter Cardiovasc Interv. 2013;81:186-94.

5. Vilalonga Pereira L, Pereira H, Vinhas $H$, Martins $C$, Calé $R$, Pereira $E$. Long-term follow-up of patients with deferred coronary intervention guided by measurement of fractional flow reserve. Rev Port 
Cardiol. 2013;32:885-91.

6. Koo BK, Yang HM, Doh JH, Choe H, Lee SY, Yoon CH. Optimal intravascular ultrasound criteria and their accuracy for defining the functional significance of intermediate coronary stenosis of different locations. JACC Cardiovasc Interv. 2011;4:803-11.

7. Cho H, Nam C, Cho Y, Yoon H, Park H, Kim H. Characteristics of Function-Anatomy mismatch in patients with coronary artery disease. Korean Circ $\mathrm{J}$. 2014;44:394-9.

8. Khan MN, Khan HS, Saif M. Fractional flow reserve: an experience of $\mathbf{1 0 0}$ patients at AFIC-NIHD. Pak Heart J. 2013;46:278-81.

9. De Bruyne B, Pijs NHJ, Kalesan B, Barbato E,Tonino $\mathrm{PAL}$,Piroth $Z$. Fractional flow reserve-guided $\mathrm{PCI}$ versus medical therapy in stable coronary disease. N Engl J Med. 2012;367:991-1001.

10. Leone AM, Porto I, De Caterina AR, Basile E, Aurelio $A$, Gardi $A$. Maximal hyperemia in the assessment of fractional flow reserve: intracoronary adenosine versus intracoronary sodium nitroprusside versus intravenous adenosine: the NASCl (Nitroprussiato versus Adenosina nelle Stenosi Coronariche Intermedie) study. JACC Cardiovasc Interv. 2012;5:402-
8.

11. Lockie T, Perera D, De Silva K, Webb I, Pattinson S, Redwood S. Impact of measuring fractional Flow reserve on decision-making in the cath lab in a cohort of patients. J Invasive Cardiol. 2010;22:413-6.

12. Nakazato R, Park HB, Berman DS, Gransar H, Koo BK, Erglis A. Noninvasive fractional flow reserve derived from computed tomography angiography for coronary lesions of intermediate stenosis severity: results from the DeFACTO study. Circ Cardiovasc Imaging. 2013;6:881-9.

13. Gould KL. Noninvasive assessment of coronary stenoses by myocardial perfusion imaging during pharmacologic coronary vasodilation: I. Physiologic basis and experimental validation. Am $\mathrm{J}$ Cardiol 1978;41:267.

14. Iguchi T, Hasegawa T, Nishimura S, Nakata S, Kataoka T, Ehara S, et al. Impact of lesion length on functional significance in intermediate coronary lesions. Clin Cardiol. 2013;36(3):172-7.

15. Brosh D, Higano ST, Lennon RJ, Holmes DR Jr, Lerman A. Effect of lesion length on fractional flow reserve in intermediate coronary lesions. Am Heart $\mathrm{J}$. 2005;150(2):338-43.

\section{PREVIOUS RELATED STUDY}

Abdul Samad, Abdul Baseer. EFFECT OF CORONARY ARTERY DISEASE DURATION ON; PLASMA LIPIDS \& LIPOPROTEINS CONCENTRATION (Original) Prof Med Jour 10(1) 55 - 57 Jan, Feb, Mar, 2003.

Fida Muhammad, Abdul Rehman Abid, Ajaz Ahmad, Shahid Imran, Nadeem Hayat Mallick. CORONARY ARTERY DISEASE; PATTERN OF CLINICAL AND ANGIOGRAPHIS FINDINGS IN YOUNG MALES (Original) Prof Med Jour 16(2) 192-197 Apr, May, Jun 2009.

\begin{tabular}{|c|l|l|l|}
\hline \multicolumn{4}{|c|}{ AUTHORSHIP AND CONTRIBUTION DECLARATION } \\
\hline Sr. \# & \multicolumn{1}{|c|}{ Author-s Full Name } & \multicolumn{1}{c|}{ Contribution to the paper } & Author=s Signature \\
\hline 1 & Dr. Naeem Asghar & Manuscript writing, Drafting & \\
2 & Dr. Liaqat Ali & $\begin{array}{l}\text { Literature review + Final } \\
\text { proof reading } \\
\text { Data collection }\end{array}$ \\
\hline 3 & Dr. Asadullah & ises \\
\hline
\end{tabular}

